\title{
Controle de estoque alimentício em um restaurante de culinária oriental
}

A fim de superarem momentos de crise e se manterem ativas e gerando resultados positivos, empresas buscam fazer adaptações que minimizem os gastos e gerem lucros. Dentre estas medidas adotadas, o controle de estoque se destaca como medida eficaz na redução de perdas e desperdícios, mantendo a qualidade dos produtos e gerando economia. O objetivo principal desta pesquisa é expor a importância do controle de estoque alimentício em um restaurante de comida chinesa, situado em um dos shoppings da capital sergipana, bem como definir as características e os impactos da ausência do controle de estoque, além de verificar como é realizado esse controle no estabelecimento em estudo. Para tanto, a metodologia da pesquisa utilizada foi a coleta de dados realizada por meio de questionário semiestruturado, contendo 11 perguntas. O questionário foi aplicado no próprio estabelecimento ao responsável pela administração do restaurante e aos funcionários que têm ligação direta com o estoque, totalizando 6 entrevistados, seguido de observação direta do local e da pesquisa bibliográfica para compor o referencial teórico deste trabalho. Os resultados apontaram que o estabelecimento precisa dar uma maior atenção ao controle de estoque, uma vez que os controles, que vinham sendo utilizados, não eram suficientes para trazer o retorno desejado do negócio.

Palavras-chave: Controle; Estoque; Gestão; Restaurante.

\section{Control of food inventory in an oriental cuisine restaurant}

In order to overcome moments of crisis and stay active and generate positive results, companies seek to make adaptations that minimize expenses and generate profits. Among these measures, inventory control stands out as an effective measure in reducing losses and wastes, maintaining product quality and generating savings. The main objective of this research is to expose the importance of food inventory control in a Chinese food restaurant located in one of the shopping malls in the capital city of Sergipe, as well as to define the characteristics and impacts of the absence of stock control, control at the study establishment. To do so, the methodology of the research used was the data collection performed through a semi-structured questionnaire, containing 11 questions. The questionnaire was applied in the establishment to the restaurant manager and to the employees who have direct connection with the inventory, totaling 6 interviewees, followed by direct observation of the site and the bibliographical research to compose the theoretical reference of this work. The results pointed out that the establishment needs to pay more attention to inventory control, since the controls that were being used were not enough to bring the desired return on the business.

Keywords: Control; Stock; Management; Restaurant.

Topic: Planejamento, Estratégia e Competitividade

Reviewed anonymously in the process of blind peer.
Received: $13 / 01 / 2018$

Approved: 22/04/2018
Jane Clesia Paiva dos Santos

Faculdade Maurício de Nassau, Brasil

http://lattes.cnpq.br/6505170927507318

janeclesiapaiva1@hotmail.com

Tatiane Heinemann Böhmer

Instituto Federal de Sergipe, Brasil

http://lattes.cnpq.br/5481836411575976

tatianebohmer@gmail.com

\section{Referencing this:}

SANTOS, J. C. P.; BÖHMER, T. H.. Controle de estoque alimentício em um restaurante de culinária oriental. Entrepreneurship, v.2, n.1, p.1827, 2018. DOI: http://doi.org/10.6008/CBPC2595-4318.2018.001.0003

DOI: 10.6008/CBPC2595-4318.2018.001.0003 


\section{INTRODUÇÃO}

O atual cenário econômico do país, que afundou o universo empresarial e os próprios empregados, em uma das mais expressivas recessões da história do Brasil, obrigou alguns centros comerciais a fazer adaptações de aspecto emergencial, a fim de superarem o momento difícil, manterem-se ativos no mercado e gerarem resultados positivos. Para isso, algumas medidas eficientes foram adotadas. Dentre estas medidas, o controle de estoque se destaca como fundamental medida, visando reduzir as perdas e desperdícios, mantendo a qualidade dos produtos e gerando economia ao atender as necessidades recorrentes da empresa no reabastecimento do estoque. Todo o empreendedor ou gestor sabe que manter um bom controle do estoque é fundamental para a obtenção do lucro. Segundo Silva et al. (2010),

Um bom controle de estoque e um monitoramento da sua movimentação são atividades indispensáveis para a lucratividade e para competitividade da empresa; porém, o custo do controle de estoque não deverá exceder os benefícios que ele possa proporcionar. (SILVA et al., 2010, citado por DANTAS, 2015)

Para Avelino (2017):

Uma maneira de se manter um controle de estoque eficiente é por meio de um bom relacionamento com os fornecedores, de modo a manter a rotatividade nos estoques com produtos novos, reduzir a possibilidade de perdas e extravios e negociar prazos de entrega. Quando há o monitoramento dos estoques, em momentos de crise e baixa demanda de clientes, os gestores poderão adiar pedidos de compras aos fornecedores com o objetivo de evitar o acúmulo nos estoques.

Sabendo desta importância para o sistema produtivo e buscando desenvolver uma abordagem concisa sobre esse tema, esta pesquisa propõe um enfoque mais realista para demonstrar a importância do controle de estoques como instrumento eficaz na redução de perdas e para aumento dos lucros da empresa.

O trabalho foi desenvolvido através da pesquisa de campo feita em restaurante de culinária oriental, situado em um dos shoppings da capital sergipana, sendo este totalmente dependente de um controle interno completo e eficaz para manter a qualidade dos seus serviços. Visto que o setor alimentício requer cuidados especiais por utilizar matéria prima e produtos mais sensíveis e, consequentemente, estragarem com maior facilidade. Desta forma, o controle efetivo de estoque tem a forma mais eficiente e eficaz de se evitarem perdas desnecessária de produtos, além de manter sempre um bom e atualizado controle de mercadorias, já que boa parte do capital da empresa está investido neste conjunto de ações. De igual modo, buscou-se destacar a importância do controle de estoques, sabendo-se que um bom gerenciamento de estoque procura manter o equilíbrio entre as necessidades da empresa e suas demandas, assim como "melhorar a qualidade dos produtos guardados na empresa" (DIAS, 2010).

Por ser o restaurante um setor onde o seu estoque é bastante diversificado em itens perecíveis "o desenvolvimento dessas atividades requer dedicação integrada por parte do gestor e de sua equipe de funcionários, tendo em vista que também é preciso estar atento às situações adversas que podem surgir na entidade" (DANTAS, 2015). Principalmente, ao se trabalhar com o setor alimentício no qual o estoque de produtos é um dos pontos mais vulneráveis, como já foi explicitado, por lidar com itens perecíveis que demanda controles rigorosos é importante atentar-se não apenas a prazos de validade, mas também às regras de estocagem e armazenamento. 
Assim, o objetivo deste artigo é destacar a importância do controle de estoque alimentício do restaurante de comida chinesa, reforçando que os produtos alimentícios são mais vulneráveis e possuem pouca durabilidade, razão por que requerem cuidados especiais para garantir a boa qualidade dos produtos, evitar desperdícios e gastos. Como objetivos específicos, o presente artigo busca: definir as características do controle de estoque; descrever os impactos da ausência do controle de estoque; verificar como estava sendo realizado o controle de estoque no estabelecimento.

Pensando o controle de estoque como medida viabilizadora do bom andamento da empresa ou sua ausência como sinônimo de transtorno, esta pesquisa se propôs a responder as seguintes questões: como é realizado o controle de estoque neste restaurante e quais as medidas adotadas para evitar possíveis perdas e desperdícios com a superlotação de produtos e até mesmo a falta de produtos?

Portanto, a justificativa e relevância desta pesquisa se estabelecem tendo em vista a importância do controle do estoque para a empresa, assim como definiu Arnold (1999) "os estoques são materiais e suprimentos que uma empresa ou instituição mantém, seja para vender ou para fornecer insumos ou suprimentos processo de produção. Todas as empresas e instituições precisam manter estoques". Se, por vez, a empresa não possui um controle de estoque ou este controle não esteja atualizado a empresa pode vir a perder produtos e vendas ou superlotar seu estoque, já que o controle de estoque de mercadoria permite identificar o quanto de capital investido a empresa dispõe, qual o valor de contas a receber e a serem pagas junto aos fornecedores.

\section{REVISÃO TEÓRICA}

\section{Estoques}

"Estoque é a composição dos materiais que não são utilizados em determinado momento, mas que exigem em função de futuras necessidades. Estocar significa guardar algo para utilização futura" (CHIAVENATO 2005). Portanto, sendo o estoque, um componente imprescindível dentro de uma empresa, o mesmo deve ser mantido sob uma significativa atenção e cuidados visando ao objetivo final que é a lucratividade da empresa.

Segundo Moreira (2002), estoque é: “[...] quaisquer quantidades de bens físicos que sejam conservados, de forma improdutiva, por algum intervalo de tempo; constituem estoques tanto os produtos acabados que aguardam venda ou despacho, como matérias-primas". Já Grant (2013) afirma que "estoque são os materiais, os produtos e as mercadorias que percorrem a cadeia de suprimentos até que sejam requeridos para transformações ou vendas aos clientes, e pôr fim ao consumidor final".

Assim, tomando por base as definições dadas por Moreira (2002) e Grand (2013), de que dentro de uma única empresa há uma variedade de estoques que vão da matéria-prima aos suprimentos transformados prontos para serem consumidos, como é o caso dos restaurantes ou empresas que trabalham no ramo alimentício, tais estabelecimentos estão vulneráveis e propícios ao desperdício, porém muitas decisões devem sempre levar em consideração os valores identificados no estoque, a demanda e o fornecimento, 
esses três devem estar correlacionados para um bom funcionamento da empresa, caso contrário, provocará de alguma forma uma perda significativa de vendas e acarretará na inexistência do estoque. Para Dias (2010):

Conhecer o estoque de uma empresa é um grande desafio, porém, a dificuldade não está em reduzir a quantidade dos produtos estocados, nem diminuir os custos. A dificuldade está em obter a quantidade correta de mercadoria estocada para atender as prioridades gerenciais de modo eficaz. (DIAS, 2010, citado por, DANTAS, 2015)

Portanto, é indispensável que o gestor atue de forma efetiva no que tange ao estoque, observandoo e controlando-o de forma que não haja incoerência em suas totalidades, mantendo um estoque que esteja correlacionado com a rotatividade, as exigências da clientela e com o crescimento financeiro da empresa. De acordo com Dantas (2015):

O motivo de o estoque ser considerado um ativo tão importante está relacionado ao fato de que o mesmo pode ser um item decisivo na estrutura de apuração do balanço patrimonial. Seu controle pode trazer bons resultados financeiro, quando aplicado corretamente pela administração da empresa.

\section{Controle}

O controle de estoque nas empresas é fundamental para a diminuição dos custos. No entanto, para se alcançar tal resultado é necessário manter um bom e eficiente controle que possa oferecer registro preciso das entradas e saídas de mercadorias. O modo como é armazenado e controlado também contribui para o aumento da lucratividade na empresa ou causar transtornos para a mesma (DANTAS, 2015). Definido assim, "o controle de estoque é todo procedimento realizado para registrar, fiscalizar e gerir a entrada ou saída de mercadorias [...]" (ARAÚJO, 2007, citado por, DANTAS, 2015). Ainda segundo destaca Dantas (2015):

O controle eficiente do estoque é essencial para a empresa manter-se competitiva e cumprir adequadamente suas atividades, além disso, é importante que não falte produtos armazenados e que não sejam compradas mercadorias desnecessárias. O prazo de entrega do produto, época do ano, demanda de procura, são itens que devem ser levados em conta na composição do estoque da empresa.

Desta forma, o controle eficiente consiste na permanente averiguação das atividades efetivas, se estão suprindo com as necessidades da empresa e se respondem ao projeto original para o qual foi projetado. Portanto "um bom controle de estoque passa primeiramente pelo planejamento desse estoque" (MARTELLI et al., 2015).

\section{A importância do controle de estoque}

O controle de estoque nas empresas é de fundamental importância para a diminuição dos custos, o controle contínuo protege a empresa de incertezas futuras e a beneficia ao realizar uma compra. $O$ fato de se saber o que tem no espaço físico da empresa, livra-a de comprar mercadorias em quantidades desnecessárias, e, ao mesmo tempo, lhe é permitido atender as demandas sem que haja prejuízos. Segundo Pozo (2008):

A função principal do controle de estoques é justamente maximizar o uso de recursos para gerenciamento dos estoques, porém, o gestor depara-se com um dilema que é causador da inadequada gestão de materiais, percebida em inúmeras empresas, e que cria problemas quanto às necessidades de capital de giro da empresa, bem como seu custo. É necessário encontrar o ponto ideal entre manter um grande volume de materiais e produtos em 
estoque para atender plenamente a demanda, o que gera uso elevado de ativos da organização e, manter volumes muito baixos de estoques para minimização dos custos, porém com atrasos em entregas, insatisfação de clientes pela falta de produtos e, principalmente, a perda do cliente.

Sendo assim, faz-se necessário o correto controle de estoques, não podendo esse ser realizado de modo independente, devendo-se aliar a gestão de estoque com os controles financeiros e à gestão de compras, visando a um aumento de ganho de capital através da otimização das compras, evitando-se aquisições desnecessárias.

É perceptível que o estoque traz consigo a importância para o desenvolvimento de uma empresa. Ao mesmo tempo em que ele pode ser um grande auxílio no sucesso da entidade, o mesmo também pode ser motivo de prejuízos consideráveis. Tudo depende de que produtos ele será constituído bem como de sua quantidade. (DANTAS, 2015)

\section{METODOLOGIA}

Para atingir aos objetivos propostos, a metodologia pautou-se na coleta e análise dos dados, o que foi procedido através de observação direta. Conforme indicado na introdução, a coleta de dados foi realizada por meio de questionário semiestruturado aplicado no próprio estabelecimento, tanto ao responsável pela administração do restaurante quanto aos funcionários que têm ligação direta com o estoque, para que fossem identificados pontos fortes e fracos do controle de estoques atual da empresa, o que foi procedido por meio de observação direta ao local. A observação direta ocorreu nos meses de agosto e setembro do ano de 2017 e teve como objetivo captar aspectos essenciais ao desenvolvimento da pesquisa. Nessa observação foi priorizado o estoque alimentício.

A pesquisa de caráter exploratório e descritivo, o que, segundo Brenner et al. (2007) consiste em uma investigação empírica sobre um fenômeno em seu contexto real, através de uma exploração intensiva de uma única unidade de estudo, seguida de revisão bibliográfica. Ela é descritiva por apresentar os procedimentos de controle existentes nos estoques do restaurante com o propósito de obter conhecimento da realidade. A fim de analisar a importância do controle de estoque alimentício do restaurante de comida chinesa e definir as características do controle de estoque, buscou-se, inicialmente, no referencial teórico e em estudos já existentes, entender os principais tipos de estoques cabíveis para essa área comercial.

O segundo objetivo da pesquisa consistiu em verificar como estava sendo realizado o controle de estoque no estabelecimento. Foi coletado por meio da aplicação de questionário semiestruturado aos responsáveis pelo estoque e ao gestor, informações sobre a organização de entradas e saídas e sobre o processo de reabastecimento do estoque.

Para contemplar o terceiro objetivo, que versa sobre os impactos da ausência do controle de estoque foi realizado por meio de uma observação direta. Que consistiu, no caso, em procedimento de natureza sensorial, ou seja, olhar, ouvir, prestar atenção nas manifestações de comportamento e condições ambientais, "[...] seu objetivo é captar com precisão os aspectos essenciais e acidentais de um fenômeno do contexto empírico" (FACHIN, 2003). 
Quanto à escolha do restaurante se deu de forma intencional, por se tratar de um estabelecimento já bastante frequentado pelo pesquisador e por este projeto ter tido boa aceitação pelo gestor, que ao entender a importância da temática, disponibilizou o estabelecimento. Participaram da pesquisa seis pessoas, tendo sido escolhidos para participar da entrevista semiestruturada àqueles em que o tempo de trabalho no restaurante deveria ser superior a três anos.

Nesse contexto, as informações obtidas no estudo em questão, através da entrevista semiestruturada e observação direta dos fatos foram analisadas qualitativamente, buscando perceber as convergências e divergências dos entrevistados e relacionando com a observação direta, descritiva e apresentados, realizando um confronto com os autores consultados, pois visa descrever as características de determinado fenômeno ou o estabelecimento de relações entre variáveis.

\section{Contexto e sujeitos da pesquisa}

A pesquisa ocorreu em um restaurante de culinária oriental, situado na praça de alimentação dos Arcos do Shopping Jardins, na capital sergipana. O Restaurante está há 12 anos no comércio e possui grande representatividade no mercado local. É um restaurante de pequeno porte, trabalha com Buffet do tipo selfservice a peso e disque-entrega com um menu bastante variado, tem capacidade para servir centenas de refeições diárias, chegando a faturar, em média, $\mathrm{R} \$ 150.000,00$ mensais (agosto e setembro/2017). Para isto, conta com vinte colaboradores, os quais ocupam os seguintes cargos: um chefe de cozinha, dois cozinheiros, um cortador, quatro balconistas, oito auxiliares de serviços gerais, dois caixas e dois gestores.

A gastronomia é um dos aspectos mais notáveis da manifestação cultural de um país e a milenar culinária chinesa é considerada uma das mais ricas, variadas e criativas do mundo. Os chineses acreditam que o preparo de alimentos é uma arte. Acreditam também que uma refeição saborosa gera felicidade, harmonia e bem-estar físico e mental.

O menu dos restaurantes brasileiros de comida chinesa,

[...] representam uma amostra muito reduzida da culinária original, oferecendo uma versão mais ocidentalizada dos pratos, com ingredientes e condimentos mais familiares. Cabe aos empreendedores do setor aprimorar a imagem da comida chinesa, demonstrando o valor nutritivo dos pratos e apresentando toda a riqueza gastronômica do oriente.

\section{RESULTADOS E DISCUSSÃO}

A pesquisa foi realizada com seis participantes, pois no restaurante não tem um funcionário específico responsável pelo estoque. Os entrevistados foram: o gerente proprietário, o chefe de cozinha, o auxiliar de cozinha, o cortador e a caixa. O questionário continha duas partes: a primeira tratava da caracterização dos entrevistados e a segunda continha 11 perguntas semiestruturadas onde o entrevistado escolhia uma resposta e comentava sobre ela; as questões tinha estreita relação com controle de estoque alimentício do restaurante. 


\section{Perfil dos entrevistados}

De acordo com os dados coletados na pesquisa, $67 \%$ dos entrevistados são do gênero masculino e 33\% do gênero feminino. Contudo, é importante destacar que esta predominância não se aplica ao total de funcionários do restaurante. A predominância do gênero masculino na pesquisa ocorreu devido aos critérios de seleção metodológica em que o tempo de trabalho no restaurante deveria ser superior a três anos.

Tabela 1: Perfil dos entrevistados

\begin{tabular}{|l|l|c|}
\hline Perfil dos Entrevistados & Total 06 \\
\hline \multirow{2}{*}{ Gênero } & Masculino & 4 \\
\cline { 2 - 3 } & Feminino & 2 \\
\hline \multirow{2}{*}{ Faixa etária } & Até 30 anos & 0 \\
\cline { 2 - 3 } & De 31 a 40 anos & 6 \\
\cline { 2 - 3 } & Mais de 40 anos & 0 \\
\hline \multirow{2}{*}{ Formação acadêmica } & Ensino Fundamental & 0 \\
\cline { 2 - 3 } & Ensino Médio/Ensino Técnico & 5 \\
\cline { 2 - 3 } & Curso Superior & 1 \\
\hline \multirow{3}{*}{ Tempo que trabalha na empresa } & De 3 a 5 anos & 0 \\
\cline { 2 - 3 } & Entre 6 e 10 & 4 \\
\cline { 2 - 3 } & Mais de 10 & 2 \\
\hline
\end{tabular}

Com relação à faixa etária, percebeu-se predomínio dos entrevistados acima de trinta anos, $67 \%$. Quanto ao nível de escolaridade, $83 \%$ dos entrevistados declararam ter nível médio completo, e apenas o gerente/proprietário declarou ter nível superior completo, correspondendo a um percentual de $17 \%$. No que diz respeito ao tempo em que trabalha no restaurante, $67 \%$ atuam no restaurante entre 6 e 10 anos, e $33 \%$ há mais de 10 anos, demonstrando uma baixa rotatividade no quadro funcional da organização.

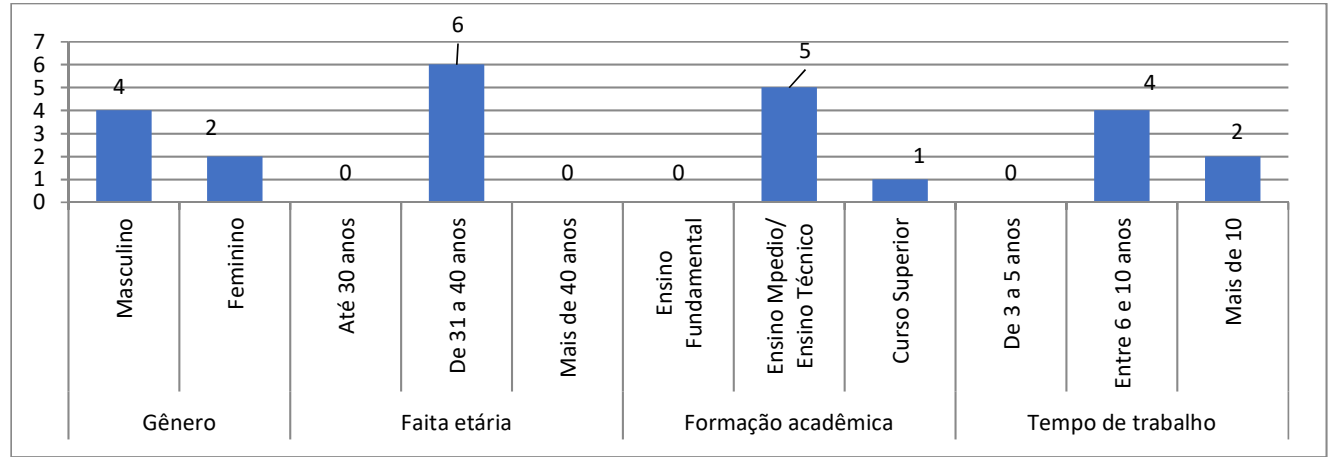

Gráfico 1: Perfil dos entrevistados

\section{Controle de estoque alimentício no restaurante}

De acordo com os entrevistados, o restaurante possui controle de entrada e saída de produtos alimentícios no estoque e que esse controle é feito obedecendo ao critério PEPS (primeiro a entrar, primeiro a sair). Esse método é adotado por fazer a avaliação do custo do material levando em consideração o custo da primeira entrada do produto no estoque, reduzindo as perdas. Há, ainda, segundo os entrevistados, revisão periódica de estoque a qual é feita com a intenção de se evitarem perdas e desperdícios causados por prazos de validade vencidos, excesso de produto ou mesmo a falta destes na hora da confecção do novo 
produto. É realizada conferência na quantidade e qualidade de produtos alimentícios comprados quando estes chegam à empresa.

Tabela 2: Controle de estoque.

\begin{tabular}{|c|c|c|c|}
\hline \multirow[b]{2}{*}{ QUESTÕES } & \multicolumn{3}{|c|}{ Resposta } \\
\hline & Sim & Não & $\begin{array}{c}\text { Não } \\
\text { sei }\end{array}$ \\
\hline Existe controle na entrada e saída de produtos alimentícios no estoque da empresa? & 6 & & \\
\hline Ocorre revisão periódica para conferência no estoque de produtos alimentícios? & 5 & & 1 \\
\hline $\begin{array}{l}\text { Há algum sistema informatizado para registrar as entradas e saídas de itens no estoque de produtos } \\
\text { alimentícios? Qual? }\end{array}$ & 6 & & \\
\hline $\begin{array}{l}\text { É realizada conferência na quantidade e qualidade de produtos alimentícios comprados, no momento em } \\
\text { que eles chegam à empresa? }\end{array}$ & 6 & & \\
\hline $\begin{array}{l}\text { Que critérios são utilizados para escolher quais os produtos serão comprados? Com qual periodicidade } \\
\text { esses produtos são pedidos? }\end{array}$ & - & & \\
\hline $\begin{array}{l}\text { Há um cadastro atualizado de fornecedores que possibilita a negociação visando obter um melhor preço } \\
\text { nas compras de produtos alimentícios realizadas pela empresa? }\end{array}$ & 6 & & \\
\hline Os gestores recebem relatórios periódicos sobre os estoques? & 2 & & 4 \\
\hline $\begin{array}{l}\text { Em sua opinião, que medidas poderiam ser implantadas na empresa para reduzir as perdas/ prejuízos } \\
\text { com os estoques de alimentos? }\end{array}$ & - & & \\
\hline $\begin{array}{l}\text { Você gostaria de fazer alguma alteração no processo de realização de estoques ou na estrutura física dos } \\
\text { estoques? Quais seriam essas mudanças? }\end{array}$ & - & & \\
\hline $\begin{array}{l}\text { No seu ponto de vista existe algum ponto fraco ou falhas no atual programa utilizado pelo } \\
\text { estabelecimento para controlar os estoques? Quais? }\end{array}$ & - & & \\
\hline
\end{tabular}

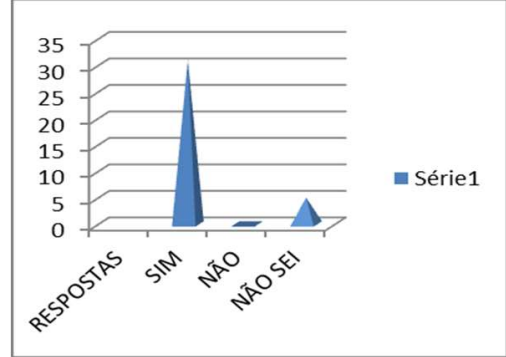

Gráfico 2: Controle de estoque

Os entrevistados foram unânimes ao enfatizar que o restaurante possui sistemas informatizados para controlar os estoques e os respectivos custos, entretanto raras vezes se utilizam desse sistema informatizado preferindo planilha manual, podendo ser essa não utilização decorrente da complexidade do sistema ou da falta de treinamento da equipe, no que tange à sua utilização. Mas, independentemente da razão, constatase que houve um investimento em um sistema que está sendo negligenciado, além disso, por se utilizar de métodos manuais, a probabilidade de erros e perdas aumenta, além de impossibilitar aos gestores um acompanhamento adequado do panorama da empresa.

O restaurante não dispõe de um funcionário específico responsável para tratar do estoque de produtos alimentícios, ficando ao encargo do chefe de cozinha, o que pode levar a empresa a sofrer perdas. Segundo Dias (2010) é importante que o encarregado pelos estoques seja um funcionário específico e que desempenhe apenas essa função para proporcionar maior segurança à empresa, devendo este ser um funcionário de confiança, atento a detalhes, muito organizado e capacitado para operar o software ou planilha de controle adotado pela empresa de forma assertiva.

Em relação aos critérios de escolha e quantidade dos produtos a serem comprados para abastecer o estoque alimentício, os sujeitos da pesquisa (chefe de cozinha e gerente) dizem ser determinados com base 
no histórico de demandas da temporada anterior e embasados na experiência do chefe de cozinha. Constatou-se, ainda, irregularidade no controle da entrada e saída dos produtos no estoque, pois era realizado de forma esporádica, e, na maioria das vezes, feita por mera análise visual.

Foi observado que o restaurante não mantinha um controle de compra adequado para compor o seu estoque, chegando com isso a faltar material o que, para não prejudicar o cardápio o item que estava faltando era comprado em supermercados próximos, chegando a se pagar um valor elevado pelo produto, o que representa considerável prejuízo financeiro.

O processo de reposição de estoque no restaurante é feito semanalmente por se tratar de produtos alimentícios que têm pouca durabilidade, isso contribui na boa qualidade do produto e na redução dos prejuízos. Portanto estes estoques exigem maior atenção, pois a falta de um produto gera gastos desnecessários, prejudica o bom funcionamento da empresa, provocando falhas na produção e acaba pagando mais pelo produto adquirido em última hora, não atingindo o resultado esperado.

Desta forma, o bom controle de estoque envolve questões importantes que não podem ser negligenciadas, como a armazenagem, que se caracteriza como o conjunto de atividades para manter fisicamente os estoques da forma adequada e pode garantir a qualidade se o mesmo for armazenado nas condições corretas. A armazenagem pode ser simples ou complexa, dependendo das características dos materiais estocados. No caso de armazenagem de alimentos, a "[...]atenção dada deve ser maior, pois os alimentos tendem a estragar se mantidos em condições incorretas" (BERTAGLIA, 2009). Para Bertaglia (2009), o prazo de validade do produto é fator fundamental para a formação do estoque, pois

Produtos com períodos de validade pequenos não podem ter estoques elevados, uma vez que se tornaram obsoletos em um curto espaço de tempo. Produtos frescos, como queijos leite resfriado, aves resfriadas, margarinas devem levar em conta a demanda e o tempo de vencimento. Essa não é uma situação simples, pois a maximização da disponibilidade de produto para atender a demanda deve ser feita limitando os riscos de obsolescência e estragos do produto (BERTAGLIA, 2009).

Essas ausências e fragilidades, evidenciadas no controle de estoque desse restaurante, devem ser corrigidas a fim de se evitarem problemas futuros, como não atingir os objetivos da empresa. A resolução dos problemas encontrados é de suma importância para a melhoria de todo o processo de produção.

\section{CONCLUSÕES}

O presente estudo buscou mostrar a importância do controle de estoque como instrumento eficaz na redução de perdas e no aumento dos lucros para a empresa. Por meio dos resultados encontrados verificou-se que no restaurante há certa irregularidade no controle de estoque, a qual pode resultar em problemas futuros, como não atingir os objetivos da empresa. Buscar corrigir os problemas encontrados é de suma importância para a melhoria de todo o processo de produção e do bom andamento da empresa. Pois, um bom e eficiente controle de estoque reflete, significativamente, no desempenho e finanças da empresa que, além de oferece informações sobre as vendas, os lucros, quantidade mínima e máxima de produtos existente no estoque, reduz as chances da empresa enfrentar problemas financeiros. 
Portanto, o intuito da pesquisa foi evidenciar a importância de um eficiente controle de estoque, a qual possibilitou identificar que o estoque é um item indispensável na composição de toda empresa comercial, seja ela de grande ou pequeno porte, e que manter um controle atualizado e organizado possibilita a empresa se manter competitiva no mercado, além de reduzir os custos, evitar o desperdício e gerar maiores lucros. Enfim, é importante salientar que controlar o estoque acaba sendo um diferencial que ajuda na credibilidade e no crescimento econômico da empresa. Por este motivo, foi sugerido que a empresa adote uma política de melhoramento no controle de seu estoque e desenvolva estratégias de aperfeiçoamento de alguns métodos já utilizados, como implantar técnicas mais precisas, separar um funcionário específico e capacitá-lo para assumir o controle de estoque, a fim de obter um aproveitamento maior das vantagens e atingir os objetivos empresariais.

\section{REFERÊNCIAS}

ARNOLD, J. R. T.. Administração de Materiais: Uma Introdução. São Paulo: Atlas, 1999.

AVELINO, D. R.. Controle interno e estoques: Um estudo em restaurante self-service e à la carte na cidade de João Pessoa-PB. Monografia (Bacharelado em Ciências Contábeis) - Universidade Federal da Paraíba, João Pessoa, 2017.

BERTAGLIA, P. R.. Logística e gerenciamento da cadeia de abastecimento. São Paulo: Saraiva, 2009.

BRENNER, E.; JESUS, D.. Manual de planejamento e apresentação de trabalhos acadêmicos: projeto de pesquisa, monografia e artigo. São Paulo: Atlas, 2007.

CHIAVENATO, I.. Administração de produção. Rio de Janeiro: Elsevier, 2005.

CORRÊA, H. L.; GIANESI, I. G. N.; CAON, M.. Planejamento, programação e controle da produção: MRP II / ERP: conceitos, uso e implantação. 4 ed. São Paulo: Atlas, 2001.
DANTAS, J. C. A.. A importância do controle de estoque: Estudo realizado em um supermercado na cidade de Caicó/RN. Monografia (Bacharelado em Ciências Contábeis) - Universidade Federal do Rio Grande do Norte, Caicó, 2015.

DIAS, M. A. P.. Administração de materiais: princípios, conceitos e gestão. 6 ed. São Paulo: Atlas, 2010.

FACHIN, O.. Fundamentos de Metodologia. São Paulo: Saraiva, 2003.

MARTELLI, L. L.; DANDARO, F.. Planejamento e controle de estoque nas organizações. Revista Gestão Industrial, Universidade Tecnológica Federal do Paraná, Ponta Grossa, v.11, n.02, p.170-185, 2015.

MOREIRA, D. A.. Administração da produção e operações. 2 ed. São Paulo: Thomson, 2002.

POZO, H.. Administração de recursos materiais e patrimoniais: uma abordagem logística. 5 ed. São Paulo: Atlas, 2008.

A CBPC - Companhia Brasileira de Produção Científica (CNPJ: 11.221.422/0001-03) detém os direitos materiais desta publicação. Os direitos referem-se à publicação do trabalho em qualquer parte do mundo, incluindo os direitos às renovações, expansões e disseminações da contribuição, bem como outros direitos subsidiários. Todos os trabalhos publicados eletronicamente poderão posteriormente ser publicados em coletâneas impressas sob coordenação da Sustenere Publishing, da Companhia Brasileira de Produção Científica e seus parceiros autorizados. Os (as) autores (as) preservam os direitos autorais, mas não têm permissão para a publicação da contribuição em outro meio, impresso ou digital, em português ou em tradução. 